\title{
NOTAS SOBRE O CONCEITO DE GRUPO POLÍTICO: CONSIDERAÇÕES SOBRE OS FERREIRA GOMES NO CEARÁ
}

\author{
Cleyton Monte ${ }^{1}$
}

Resumo: O artigo a seguir tem como objetivo refletir teórica e empiricamente sobre as características de grupos políticos no Ceará. Essa empreitada se concretiza ao se percorrer as principais formações políticas da histórica do Ceará pós-1964. Partindo da composição dos grupos que dominaram o estado ao longo da ditadura militar, liderados pelos coronéis César Cals, Adauto Bezerra e Virgílio Távora, passando pelo predomínio do governador Tasso Jereissati e chegando, finalmente, ao protagonismo do grupo dos Ferreira Gomes. Este último será analisado em seus pormenores, destacando os vínculos familiares, base local, migrações partidárias, lógica de atuação e movimentos contemporâneos. Defende-se que o arranjo dos grupos agrega elementos das gramáticas tradicionais e modernas da política e funciona paralelo ao sistema partidário estadual, oferecendo caminhos para se compreender as estratégias, carreiras e alianças produzidas pelos atores e instituições democráticas.

Palavras-chave: Grupos. Democracia. Ferreira Gomes. Ceará.

\section{NOTES ON THE CONCEPT OF POLITICAL GROUP: CONSIDERATIONS ABOUT FERREIRA GOMES IN CEARÁ}

\begin{abstract}
The following article aims to reflect theoretically and empirically on the characteristics of political groups in Ceará. This endeavor is realized by going through the main political formations of Ceará's history after 1964. Starting from the composition of the groups that dominated the state during the military dictatorship, led by the colonels César Cals, Adauto Bezerra and Virgílio Távora, passing by the predominance of the governor Tasso Jereissati and finally reaching the leading role of the Ferreira Gomes group. The latter will be analyzed in detail, highlighting family ties, local base, party migrations, logic of action and contemporary movements. It is argued that the arrangement of groups aggregates elements of traditional and modern grammars of politics and works in parallel with the state party system, offering ways to understand the strategies, careers and alliances produced by democratic actors and institutions.
\end{abstract}

Keywords: Groups. Democracy. Ferreira Gomes. Ceará.

\section{Introdução}

Embora as descrições e análises da política estadual no Brasil, e mais especificamente no Ceará sempre recorram à nomeação de "grupo político", não se atribui ao termo um estatuto teórico.

\footnotetext{
${ }^{1}$ Doutor em Sociologia (UFC). Professor da UFC e da Faculdade Cearense. Pesquisador do LEPEM (Laboratório de Estudos sobre Política, Eleições e Mídia da UFC) e articulista dos jornais O POVO e SEGUNDA OPINIÃO. E-mail: cleytonvmonte@gmail.com
} 
Em que medida é possível considerá-lo mera herança do padrão tradicional da política ou na verdade ele comporta especificidades e flexibilidade que o ajustam ao padrão atual da política? Essa questão norteia o presente artigo.

O objetivo dessa pesquisa é verificar a presença, marcas e transformações dos grupos políticos no Ceará. Seguimos um percurso histórico. Partindo da composição dos grupos que dominaram o estado ao longo da ditadura militar, liderados pelos coronéis César Cals, Adauto Bezerra e Virgílio Távora, passando pelo predomínio do governador Tasso Jereissati e chegando, finalmente, ao protagonismo do grupo dos Ferreira Gomes. Este último será analisado em seus pormenores, destacando os vínculos familiares, base local, migrações partidárias, lógica de atuação e movimentos contemporâneos.

De 2006 a 2018, o grupo dos Ferreira Gomes conseguiu consolidar-se como a principal força política do Ceará. Esse feito se deu a partir de uma bem-sucedida rede de alianças, integrada pela maioria dos deputados federais, deputados estaduais, prefeitos e vereadores, além do apoio formal das grandes forças partidárias do Estado, compondo uma articulação que produziu um dos arranjos mais poderosos do Nordeste na atualidade. Esse aglomerado, marcado pela heterogeneidade de lideranças e partidos, laços familiares, apoio da gramática lulista e extremo pragmatismo, pode oferecer pistas importantes sobre os desdobramentos de um grupo político na atualidade.

O presente artigo divide-se em quatro partes. A primeira tem como foco analisar teoricamente esse tipo de formação política. A segunda parte acompanha os passos e marcas dos grupos políticos pós-1964. Em seguida, na terceira e quarta partes, o grupo dos Ferreira Gomes torna-se objeto central da investigação, abordando seus elementos constitutivos e articulações contemporâneas. Nas considerações finais, faz-se um apanhado dos pontos analisados ao longo do artigo e destaca-se a necessidade de pesquisas futuras sobre o tema.

\section{Grupo político: o que isto quer dizer?}

A análise da política tradicional brasileira destaca suas raízes rurais na elucidação das formas de controle sobre os eleitores. O poder econômico dos proprietários de terra se convertia diretamente 
Revista NEP - Núcleo de Estudos Paranaenses, Curitiba, v. 5, n. 2, dez. 2019

em controle político, ou seja, os votos daqueles reconhecidos como "gente do coronel sicrano" não precisavam ser conquistados, na medida em que considerados obrigação devida aos seus donos. Aceitava-se o patrimonialismo, definido pela ausência de fronteiras entre o público e privado, como condição "natural" da política. Do mesmo modo o personalismo estaria na origem da política tradicional remetendo para a noção correlata de "chefe político" atribuída aos que na esfera dos municípios, de modo especial do interior, e na política estadual, detinham "bases eleitorais" que lhes garantisse força política nas disputas eleitorais.

A expressão "chefe político" tem origem no contexto de sociedades predominantemente rurais nas quais o domínio dos patrões se estendia de forma direta sobre as relações sociais e políticas, justificando assim a nomeação pejorativa de "currais eleitorais". O poder de um chefe político é avaliado por sua capacidade de controle de votos em um determinado território, seja de forma única ou compartilhada e que são consideradas suas "bases eleitorais". A noção "bases eleitorais assume significados distintos quando aplicada a diferentes tipos de eleições. Nas municipais reporta-se a laços mais diretos estabelecidos entre candidatos e eleitores caucionados por formas de atendimento de demandas econômicas ou troca de favores que resultam em uma adesão relativamente estável traduzida em votos. Nas eleições estaduais e federais, as relações dos candidatos com os eleitores na conquista de votos são mediadas pelos chamados "chefes políticos" municipais, que podem ser prefeitos, vereadores ou lideranças com influência sobre segmentos do eleitorado. A origem familiar é uma característica invocada para justificar a origem e o prestígio de chefes de grupos políticos.

No Brasil, as expressões chefes políticos, currais eleitorais e voto de cabresto continuam a ser utilizadas mesmo quando a urbanização, industrialização, mudanças na economia rural e ampliação da presença do Estado alteraram significativamente formas anteriores de controle social e político. Vale ressaltar que, apesar de não termos no Brasil eleições distritais, deputados estaduais e federais consideram como suas "bases eleitorais" os municípios ou regiões onde obtiveram significativa concentração de votos e para as quais direcionam grande parte de suas atividades parlamentares na busca de atender "pleitos" daqueles que considera representar mais diretamente. ${ }^{2}$

Em síntese, os dados mencionados possibilitam algumas considerações embrionárias sobre a noção de grupo político sejam feitas. A noção remete para a política real, desde a instância de laços entre políticos e eleitores nas "bases eleitorais municipais" até relações que se estabelecem com

\footnotetext{
${ }^{2}$ Ver BEZERRA, 1999.
} 
candidatos ao parlamento e a cargos majoritários que buscam nos chefes políticos municipais apóio para a constituição de redutos eleitorais que lhes garantam votos necessários para serem eleitos.

A organização de um grupo político pressupõe a existência de um chefe político com características pessoais de liderança e com possibilidades efetivas de contatos políticos ao nível da política estadual ou nacional que tornem plausíveis suas pretensões de agregar seguidores políticos. A noção de grupo político permite o entendimento das características tradicionais da política brasileira (patrimonialismo e personalismo) que se amoldam ás exigências da modernização das relações políticas. A "política do favor" tende a assumir formas menos explícitas e individualizadas de troca entre candidatos e eleitores (caso da compra de voto por dinheiro) para converter-se em distribuição preferencial de recursos públicos direcionados ás bases eleitorais de grupos políticos.

As disputas ao nível municipal ou estadual são travadas principalmente entre grupos políticos que se reconhecem como antagônicos em suas pretensões de conquista de poder. A ligação de grupos políticos aos partidos depende das oportunidades que são oferecidas às suas lideranças para disputar cargos políticos que os fortaleçam face aos seus opositores. Os partidos constituem-se a face institucional do jogo político, porém seu tamanho e importância nos Estados variam em função da força dos grupos políticos que circunstancialmente neles se abrigam. A dimensão das coligações partidárias firmadas por grupos políticos hegemônicos, que em determinados casos incluem mais de 20 partidos, é indicativa das dificuldades postas á formação de grupos políticos de oposição com capacidade significativa de confrontação, o que contribui para acentuar o situacionismo.

O discurso político nas disputas municipais se moderniza com o uso de formas de comunicação midiáticas e estratégias de marketing, mas o que se pretende é menos transmitir um “projeto de gestão", mas oferecer a perspectiva de vitória da qual seus seguidores serão os principais beneficiários. A adesão a grupos políticos é basicamente pragmática e não implica em lealdade duradoura ou incondicional a seus chefes. O fenômeno da "infidelidade" partidária, da migração partidária, da criação de novos partidos, explica-se principalmente por interesses de chefes de grupos políticos na luta por garantir ou expandir suas posições de poder. A hipótese proposta é que a noção de grupo político ajusta-se à compreensão da política cearense em diferentes contextos políticos não apenas do passado, mas da atualidade. 


\section{Grupos políticos na história cearense}

Para a maior parte dos analistas, os parâmetros da política tradicional, condensados no conceito de coronelismo, predominantes no Brasil durante a chamada República Velha, tenderam a diluir-se, ou mesmo desaparecer face ao avanço dos processos de urbanização e industrialização registrados a partir da década de 30 do século XX quando o direito de voto foi estendido à grande parte da população. A permanência da política tradicional é admitida principalmente com marca de regiões que não acompanharam o desenvolvimento nacional, caso do Nordeste, ou ainda quando se reconhece a existência de mazelas de uma herança a serem reparadas por propostas de reformas políticas. Entretanto, o clientelismo como "política do favor", ou seja, determinação do voto por relações assimétricas de poder, era "naturalizado" como traço da política brasileira e somente mais recentemente, tem ganhado destaque na mídia ao ser reconhecido como corrupção eleitoral sujeita a sanções legalmente previstas.

Alguns exemplos da política cearense são ilustrativos disso. Mesmo com a centralização política do período militar pós-1964, os grupos políticos chefiados pelos coronéis Virgílio Távora, César Cals e os Irmãos Bezerra dominaram a política estadual. Oficializada a divisão da ARENA em sublegendas, o partidarismo amoldava-se às disputas entre os grupos políticos existentes nos municípios. As disputas entre situação e oposição, aconteciam com maior freqüência entre grupos políticos filiados ao mesmo partido, a ARENA. Considerando que a escolha do governador não se fazia por voto direto, mas por indicação do governo militar, quem ocupava o cargo cuidava de organizar ou fortalecer seu grupo político nos municípios demonstrando sua força com a eleição de um maior número possível de prefeitos, vereadores, deputados federais e estaduais. Cada um dos três chefes de grupos políticos vinculava-se a chefes políticos municipais que o apoiavam e eram por ele apoiados. A lealdade ao chefe dificultava a fragmentação fortalecendo os laços de coesão interna de um grupo político.

Com a redemocratização na década de 80 as posições dos grupos políticos anteriores foram duramente atingidas. Candidato ao governo do Estado de 1986, o empresário Tasso Jereissati derrota o coronel Adauto Bezerra, estigmatizado como representante das "forças do atraso". Quais readaptações acontecem com as forças políticas locais pós-redemocratização? A questão posta é por 
Revista NEP - Núcleo de Estudos Paranaenses, Curitiba, v. 5, n. 2, dez. 2019 Dossiê Oligarquias do Nordeste no Brasil

ISSN: $2447-5548$

demais ampla para ser aqui respondida, o que nos leva a destacar apenas alguns aspectos no que se refere a organização de novos grupos políticos. Tasso não construiu sua carreira política em bases municipais, exatamente por seu início ter acontecido no retorno á democracia, momento de inflexão da política nacional. Para conservar a hegemonia na política cearense por mais de 20 anos dificilmente poderia dispensar a busca de apóio de chefes políticos municipais.

A regra do adesismo não apenas permaneceu, mas se fortaleceu, ajudando a entender os ciclos políticos de longa duração que se instalaram na política cearense pós-redemocratização. A oposição passa a ser praticamente inexistente, sugerindo que integrar o grupo político hegemônico é fator de sobrevivência política na medida em que o atendimento de demandas políticas das bases eleitorais depende cada vez mais de acesso a recursos e programas governamentais. Perde importância o velho clientelismo feito com recursos próprios.

Outro fator de diferenciação do Tassismo é que em sua origem ele se apresentou como representante de uma associação empresarial, o CIC (Centro Industrial do Ceará), e seu discurso era o de modernização da política cearense. É pertinente considerar que uma associação empresarial, que supostamente paira acima de personalismos, seja compatível com a existência da forma tradicional de funcionamento de grupos políticos? Embora alguns membros do CIC tenham participado da equipe dos governos Tasso, essa não foi uma regra geral. É inegável que o domínio personalizado persistia e se revela na denominação de uma era política por quem a protagonizou: tassismo ${ }^{3}$.

Uma gestão mais centralizada nos moldes empresariais teria reduzido o poder de chefias políticas locais? Por outro lado faltava a Tasso uma base familiar a invocar como origem e legitimidade de sua liderança. Como já dito, ele entrou na política estadual na posição de governador, sem uma carreira política percorrida em cargos anteriores. Ao término do seu primeiro governo em 1990, Ciro Ferreira Gomes elege-se como seu sucessor a ele cabendo a tarefa de preservar o que ficou conhecido como "projeto mudancista". Como governador, Ciro não trabalhou para se tornar chefe de um grupo político próprio, sua imagem manteve-se vinculada ao seu patrono, que retorna ao governo

\footnotetext{
${ }^{3}$ O "governo das mudanças", "tassismo" ou a "Era Tasso" foi o período de vinte anos, iniciado em 1987, marcado pelo domínio político do ex-governador Tasso Jereissati no estado do Ceará. Os estudos sobre esse período destacam o papel modernizante do grupo liderado por Tasso, a política de investimentos em grandes obras, a racionalização da administração pública e a importância da mídia, mas também enfocam: o distanciamento dos movimentos sociais, o descaso com os servidores públicos e o agravamento da miséria (FARIAS, 2012; NOBRE, 2008; HEREDIA, 2008; ARRUDA, 2002).
} 
em 1994 e é reeleito em 1998 (com vitórias em $1^{\text {o }}$ turno), configurando um ciclo político com longevidade e hegemonia nunca antes alcançadas na política cearense.

Em 2002, Tasso elege-se para o senado e em uma disputa eleitoral muito competitiva Lúcio Alcântara, candidato do seu partido, o PSDB, é eleito para o governo do Estado. Entretanto, a conjuntura nacional com a eleição de Lula para presidente, sinalizava para o declínio do tassismo, sem que outro grupo político ganhasse visibilidade na política estadual. Lúcio Alcântara, de família política de tradição desde antes de 1964, não se empenhou no decorrer de sua gestão em construir um grupo político próprio e, por conseqüência, não se fortaleceu na condição de chefe político estadual.

Em 2006, frustrado na pretensão de contar com o apoio de Tasso para sua reeleição, Lúcio Alcântara percebe, tardiamente, que lhe faltavam bases eleitorais próprias, ou seja, ele não angariara a seu favor os ganhos do situacionismo e não lhe restava tempo nem legitimidade para se apresentar e se reconhecido como candidato de oposição. Resultado inevitável: derrota para Cid Ferreira Gomes, (irmão de Ciro) filiado ao PSB, que contava com o apóio informal de Tasso e apresentava-se coligado ao PT e PMDB, forças políticas em ascensão no cenário nacional.

A vitória de Cid ao governo do Estado oferece pistas sobre a ação dos grupos políticos que transcenderia a dos partidos políticos, que funcionam principalmente como siglas institucionais nos quais se abrigam em função de interesses conjunturais. Não é a filiação a um determinado partido que marca a identidade de um grupo político, mas o reconhecimento pessoal de quem exerce sua chefia. Como implícito na própria nomeação dada pela mídia "os irmãos Ferreira Gomes" passam a ser reconhecidos como chefes de um "grupo político" estadual cuja gramática é determinada não por filiações partidárias, mas pela capacidade de agregar seguidores que os apóiam e a quem retribuem apoio político.

\section{Os Ferreira Gomes: elementos constitutivos}

A família Ferreira Gomes é de origem portuguesa, porquanto os capitães Domingos Ferreira Gomes e Bernardino Ferreira Gomes são naturais de Leiria, em Portugal. Os primeiros nomes do clã, que desembarcaram no porto de Acaraú, em 1790, tornaram-se, posteriormente, importantes proprietários de terra e criadores de gado - atividades que a família acompanharia por muito tempo. 
Revista NEP - Núcleo de Estudos Paranaenses, Curitiba, v. 5, n. 2, dez. 2019 Dossiê Oligarquias do Nordeste no Brasil

ISSN: 2447-5548

Ao longo dos séculos XVIII e XIX, os Ferreira Gomes assumiram importantes funções públicas em Sobral, tornando-se expoentes da política na zona Norte cearense. Os primeiros prefeitos de Sobral, tão logo a República se instalou no país, foram Vicente César Ferreira Gomes, em 1890, e o TenenteCoronel José Ferreira Gomes, logo em seguida, em 1892. Este último, bisavô de Cid, foi chefe do Partido Conservador na região (ARRUDA, 2012; FIRMO, 2012).

Os laços familiares foram fundamentais no início da carreira dos irmãos Ferreira Gomes. Ciro Gomes nasceu em Pindamonhangaba/SP (1957). Formou-se em Direito pela UFC. Mais velho dos irmãos, deu início à sua carreira política como deputado estadual, em 1982, pelo PDS. Recebeu o incentivo do pai, que já o via como continuador da tradição política da família, tendo-o indicado procurador do município de Sobral na época da sua gestão como prefeito (FIRMO, 2012). Ciro atende aos desejos do pai, já contando com experiência em outras campanhas e com uma razoável formação jurídica, após tentar disputar a vice-presidência da UNE, em 1979. Nesse período, a família integrava o "grupo cesista", liderado pelo então governador César Cals.

Nas eleições de 1982, Ciro Gomes fica na suplência, mas assume quase todo o mandato, vindo a se eleger de fato em 1986, pelo PMDB, no mesmo ano em que Tasso Jereissati e o grupo de empresários por ele liderado chegam ao poder no Ceará. Nesse momento, Ciro se torna líder do primeiro governo das mudanças e inicia uma relação duradoura com o governador Tasso Jereissati, estabelecendo uma ligação que se tornaria determinante para a ascensão do grupo de Sobral. Em 1988, Ciro é indicado para concorrer à prefeitura de Fortaleza, ao mesmo tempo em que o irmão Cid ingressava na vida partidária, disputando o cargo de vice-prefeito de Sobral, na chapa do padre Zé Linhares. Enquanto Ciro se consagrava prefeito de Fortaleza, numa das eleições mais disputadas da história da capital cearense, Cid, por uma pequena margem de votos, experimenta a sua primeira derrota para Zé do Prado, uma das principais lideranças de Sobral (FIRMO, 2012).

Cid Ferreira Gomes nasceu em Sobral/CE (1963). Formou-se em Engenharia Civil pela UFC. Apesar de engenheiro, Cid nunca exerceu de fato a profissão, pois logo após concluir a faculdade, passou a assessorar o irmão Ciro Gomes, despontando como político potencial de uma tradicional família de classe média cearense. Parafraseando Lasswell (1984), seu sonho parecia estar voltado para a "direção dos homens", não para a coordenação de obras, fenômeno já observado nos tempos da faculdade, quando presidiu o Centro Acadêmico de seu curso. 
Revista NEP - Núcleo de Estudos Paranaenses, Curitiba, v. 5, n. 2, dez. 2019

Após a derrota em Sobral, Cid foi convidado por Tasso Jereissati para ser coordenador político regional do Estado do Ceará, constituindo-se um articulador político do governo na região Norte. Na eleição seguinte, em 1990, já no PSDB, Ciro candidatou-se, por indicação de Tasso, e se elegeu governador do Ceará. Cid, por sua vez, iniciou a carreira de deputado estadual, tornando-se, então, líder do PSDB no Legislativo estadual. De 1993 a 1995, assumiu a importante primeira secretaria do parlamento e, em 1996, aos 32 anos, no segundo mandato de deputado, foi escolhido, por unanimidade, presidente do Legislativo cearense. Contudo, para compreender a dinâmica do poder dos Ferreira Gomes, deve-se atentar para a construção da hegemonia do grupo em Sobral.

Historicamente, os grupos políticos brasileiros, antes de conseguir estender sua ação para um raio de influência maior, buscam garantir a hegemonia sobre um município ou região, ocupando cargos de destaque e negociando seu apoio eleitoral diretamente com os mandatários estaduais. Esse caminho foi trilhado pelos Ferreira Gomes, que, desde meados da década de 1990, garantiam o domínio ininterrupto sobre a cidade de Sobral, o município mais importante do Norte cearense. Apesar de outros membros da família já terem ocupado o Executivo municipal, Cid foi o primeiro a demarcar um espaço de independência para o grupo.

A campanha de Cid Gomes à prefeitura de Sobral em 1996, ao mesmo tempo em que chamava a atenção para o valor da tradição de sua família, destacando as ações de seu pai como prefeito e do irmão como governador e ressaltando que faria Sobral voltar aos tempos gloriosos, colocava-se como representante da política moderna, que iria revolucionar a administração da cidade, assim como Tasso Jereissati e Ciro estavam fazendo no âmbito do estado. Acusava seus adversários, Cândida Figueiredo e Marcos Prado, de legítimos representantes do clientelismo político e de grupos políticos atrasados. Dessa forma, Cid Gomes trazia para a sua campanha elementos do imaginário tradicional e moderno na política (FREITAS, 2000). Sua coligação agregou lideranças da esquerda, principalmente do PT, e correligionários do PSDB, fenômeno que seria repetido futuramente ao administrar o estado.

Após vencer com $63 \%$ dos votos válidos, Cid Gomes iniciou a administração "Sobral no rumo certo", contando com secretários do PT e do PSDB. Inaugurou uma era de grandes transformações, levando muitos moradores a afirmarem que "Sobral é outra depois de Cid" (FERREIRA, 2013). Entre as ações de suas duas gestões (1997-2004), destacam-se a instalação da fábrica gaúcha GRENDENE, que chegou a empregar mais de 10.000 mil funcionários, a preservação e o tombamento de prédios 
Revista NEP - Núcleo de Estudos Paranaenses, Curitiba, v. 5, n. 2, dez. 2019

históricos, a implantação do Programa Saúde da Família, o planejamento urbano e a revitalização do rio Acaraú, a qualificação dos servidores públicos, o desenvolvimento do polo universitário, a modernização dos serviços públicos, a reforma do Beco do Cotovelo e, o que é considerado pela população e membros do grupo como o maior legado de suas gestões, a qualificação da educação, levando o município a figurar nos índices nacionais como umas das melhores redes de ensino do país (FERREIRA, 2013).

Ao longo da década de 1990, os irmãos Ciro e Cid Gomes trilharam, apesar da permanência sempre no mesmo partido, caminhos distintos (CARVALHO e AQUINO, 2011). Ciro, o irmão mais velho, buscou construir uma carreira nacional, não entrando em conflito com a liderança e planos de Tasso Jereissati no Ceará. Chegou a disputar duas vezes a presidência da República (1998 e 2002) e ocupar dois ministérios em períodos distintos. Cid, o mais novo, fez o caminho inverso, articulou apoios no Legislativo cearense, elegeu-se, em 1995, presidente da Assembleia, por unanimidade, e pavimentou, aos poucos, o caminho que o levaria a concorrer e ganhar a prefeitura de Sobral. Orgulha-se de ser um homem do interior, tendo sua vida inteira voltada para a política local (ALCE, 05/04/14). Utilizando famosa tipologia de Weber (2009), os irmãos demonstram ser lideranças que vivem da política e, até quando não estão ocupando cargos públicos, envolvem-se em articulações partidárias. Utilizam as redes sociais intensivamente.

Apesar de se apresentarem como políticos de classe média e defenderem em seus discursos bandeiras progressistas como a transparência dos atos do Estado, a modernização dos serviços públicos, o aumento dos investimentos em educação e a redução da miséria, Ciro e Cid não conseguiram, ao longo de suas carreiras, delinearem programa que servisse para pautar suas decisões. Ao se comparar sua lógica de atuação com a do grupo do CIC, as diferenças são enormes. No final da década de 1970, os empresários daquela entidade se reuniam para discutir com entidades da sociedade civil uma série de críticas ao modelo econômico desenvolvido pelos governos militares, a necessidade de revolucionar a administração pública cearense e o papel do Estado nesse processo. Muitos pontos originados nos seminários do CIC foram incluídos nas ações do primeiro governo Tasso.

A dinâmica do grupo dos Ferreira Gomes segue o caminho inverso. Os rituais de interação entre os membros ocorrem sempre em períodos pré-eleitorais e/ou na movimentação que antecede a 
Revista NEP - Núcleo de Estudos Paranaenses, Curitiba, v. 5, n. 2, dez. 2019

migração partidária. Não há uma agenda de discussão com a sociedade civil e as ações são deliberadas na cúpula e disseminadas nessas reuniões, que guardam um papel básico: o pragmatismo eleitoral. O grupo dos Ferreira Gomes não se resume a um único partido. Sua organização assemelha-se ao modelo metapartidário dos carlistas na Bahia.

A influência dos Ferreira Gomes é percebida em várias agremiações. Os casos do prefeito de Sobral, Veveu Arruda, e do governador Camilo Santana, ambos filiados ao PT, evidenciam essa lealdade. Por questões metodológicas, trata-se, aqui, exclusivamente dos partidos que receberam as principais lideranças do grupo. Essas agremiações passaram a encarnar a lógica do grupo e rapidamente percebem seu número de filiados crescer vertiginosamente. As lideranças que, circunstancialmente, pertençam a partidos diferentes dos abraçados pelos irmãos Ferreira Gomes, sofrem pressões vindas de outros atores, obrigados a lidar diretamente com uma série de constrangimentos. Assim, oportuno é assinalar a movimentação do grupo em seus principais partidos.

No PDS, partido que substituiu a extinta Arena, a legenda oficial da ditadura militar, Ciro Gomes disputou, em 1982, uma vaga para deputado estadual. Muito mais ligado ao grupo do governador César Cals. No final do mandato de Gonzaga Mota, Ciro acompanhou o movimento liderado por Tasso Jereissati dentro do CIC e começou a apoiar o projeto, iniciando uma parceria de longa duração. Nas eleições de 1986, a política cearense passou por transformações radicais em todos os setores, construindo uma verdadeira recomposição de forças. Com um posicionamento bem mais destacado, Ciro, aos 29 anos, foi escolhido para liderar o governo Tasso na Assembleia, num período de grande tensão. Com o fortalecimento dos laços entre a família Ferreira Gomes e o governador, recebeu de Tasso o apoio decisivo para se tornar um político de destaque, fato que o levaria à prefeitura de Fortaleza em 1988 e ao governo do Estado em 1990.

No final da década de 1980, surgiu o PSDB, com um grupo de dissidentes do PMDB, liderado por políticos de São Paulo, como Mário Covas e Fernando Henrique Cardoso, e do Ceará, agrupando os jovens empresários já no poder. Acompanhando os passos de Tasso Jereissati, Ciro Gomes e seus aliados migraram para o PSDB em 1988. Exerceu papel de destaque nessa sigla, ocupando o Ministério da Fazenda no governo Itamar Franco, em 1994. Em 1997, o grupo trocou o PSDB pelo PPS, após uma série de ofensivas contra o presidente Fernando Henrique Cardoso, que iam desde críticas à equipe de governo, passando por polêmicas envolvendo os cortes de gastos até às 
privatizações e às relações internacionais.

No início dos anos 2000, já estava evidente que o mudancismo inaugurado por Tasso passava por um período de esgotamento eleitoral. Compreendendo as circunstâncias locais e já se aproximando da lógica lulista, os Ferreira Gomes começaram a construir uma trajetória de autonomia frente à liderança de Tasso Jereissati. A partir de 2004, começavam a mostrar autonomia em relação ao grupo de Tasso. Contudo, a relação com a direção nacional do partido se tornou muito delicada, principalmente após o presidente da sigla, Roberto Freire, anunciar oposição ao governo Lula. Ocupando o Ministério da Integração Nacional, Ciro articula a ida do seu grupo, já contando com importantes prefeituras, ainda em 2005, para o PSB, tradicional partido da esquerda brasileira e um dos apoiadores tradicionais do PT.

O partido, apesar de sua tradição e inserção nos movimentos sociais, não ocupava cargos de destaque no Estado. Com o ingresso dos Ferreira Gomes, tornou-se, nos anos seguintes, uma das maiores forças políticas locais. Em 2006, com a chegada de Cid ao governo do Estado, o PSB disputou espaço com o PSDB, partido ainda hegemônico no Legislativo e nas prefeituras do interior. Diferente do apoio imediato concedido nos outros partidos, possibilitando uma movimentação interna sem críticas, o PSB já possuía lideranças de destaque no estado, a chamada ala histórica, cujo maior representante era o ex-deputado federal Sérgio Novais.

Presidindo o PSB, Cid Gomes elevou, nas eleições de 2012, a sigla à condição de maior força partidária do estado, alcançando espaços em todas as regiões e, principalmente, garantindo a prefeitura de Fortaleza. O partido já contava com 40 prefeituras, 10 deputados estaduais e 4 federais, numa dimensão ainda bem reduzida, se comparada com o peso do PSDB nos governos Tasso. Em meados da década de 1990, os tucanos ocupavam sozinhos quase todas as prefeituras e sua hegemonia parlamentar era bem maior, chegando a conquistar, em 1994, 20 cadeiras na Assembleia Legislativa. Isso revelou que a expansão do partido do grupo aconteceu paralelamente ao crescimento de siglas aliadas, expondo uma estratégia de compartilhamento de espaços. Assim, PT, PMDB e PCdoB tiveram suas representações elevadas na última década. Após uma série de conflitos internos, o grupo migra para o pequeno e recém criado PROS.

Com as eleições de 2016 já bem próximas, o grupo visualizava as dificuldades de expansão 
em um partido com pouca estrutura, relevância e tempo de exposição na TV. As discordâncias com a cúpula nacional do PROS se avolumavam. Cid e Ciro Gomes criticavam a aproximação do partido com as estratégias de Eduardo Cunha em confrontar o governo Dilma. Começavam as articulações para as eleições de 2016 e 2018. Diante do desgaste do lulismo e da intensa movimentação de Ciro Gomes, cogitou-se, também, a articulação do grupo para mais uma empreitada nacional.

\section{Os movimentos contemporâneos dos Ferreira Gomes}

A migração partidária não seria o problema, tendo em vista o histórico de transferência dessas lideranças. Depois de sondar vários partidos, acertaram a filiação em massa ao PDT. Em setembro de 2015, o PDT se tornou a força mais importante da Assembleia Legislativa, com 12 deputados. Após uma série de discussões com os partidos da base aliada, realizou-se, às vésperas do prazo estabelecido pela justiça eleitoral, a indicação da chapa, encabeçada por Camilo Santana, deputado estadual petista e ex-secretário nas duas gestões de Cid, tendo como companheira de chapa a ex-secretária da Educação, Izolda Cela, e para o Senado, o também deputado e ex-secretário da Fazenda, Mauro Filho. Compunha-se, assim, uma chapa de perfil mais técnico, com nomes ligados diretamente ao governador e, principalmente, aos resultados de sua administração. A coligação situacionista, "Para o Ceará seguir mudando", agregou dezoito agremiações de diferentes tendências, como o PP e o PCdoB, formando uma coligação ideologicamente inconsistente.

O candidato do governo destacava em sua campanha que iria finalizar as obras inconclusas nas gestões Cid Gomes, principalmente as estruturais, como a Companhia Siderúrgica do Pecém, o Cinturão das Águas e as linhas do Metrô de Fortaleza. Reconhecia a necessidade de dialogar mais com a sociedade e reavaliar os problemas enfrentados com o aumento dos índices da violência, afirmando que a área da segurança reclamava novas ideias, como a requalificação do Ronda do Quarteirão, e prometia a construção de mais hospitais regionais, habitações populares e escolas profissionalizantes, demonstrando plena sintonia com as ações realizadas nos governos Cid Gomes. O principal candidato da oposição, Eunício Oliveira, destacou em sua campanha e nos debates, a crise 
Revista NEP - Núcleo de Estudos Paranaenses, Curitiba, v. 5, n. 2, dez. 2019

da segurança pública, a sua independência com relação a padrinhos políticos, numa forte referência a Camilo Santana, que se apresentou como candidato de Cid, Lula e Dilma.

O desgaste do governo estadual foi percebido ao longo da campanha. Segundo pesquisa O Povo/Datafolha, divulgada em agosto de 2014, o governo Cid apresentou 46\% de aprovação entre os eleitores cearenses (ótimo/bom). Mesmo sendo bem avaliado, perdera 19 pontos, se comparado com o fim do primeiro mandato, em 2010, quando divulgada a pesquisa informando que o governo apresentava $65 \%$ de aprovação (ótimo/bom). Nessa eleição, a competitividade retornou às disputas para o governo, com equilíbrio no número de apoios de lideranças e estrutura de campanha.

O pleito se estendeu para o segundo turno, com Camilo vencendo por uma pequena margem de votos (47\% a 46\%). Um dos mais sérios opositores, Tasso Jereissati (PSDB), ganhou a única vaga em disputa para o Senado, num fenômeno raro, pois nas eleições anteriores o governador em exercício sempre conseguiu eleger o seu candidato. No segundo turno, prevaleceu a competitividade entre os candidatos Camilo Santana e Eunício Oliveira, com as pesquisas eleitorais apontando um leve favoritismo para o primeiro. No final, Camilo ganhou com 53,35\% dos votos, enquanto o senador peemedebista obteve 46,65\% dos votos válidos, fortalecendo o grupo dos Ferreira Gomes, responsável direto pela escolha de Camilo e pelas articulações no interior. A aliança nacional não foi fragilizada. A presidente Dilma Rousseff, apesar de não ter participado das eleições no estado, conseguiu $77 \%$ dos votos, a terceira maior votação da petista no país.

A eleição de 2018 foi completamente singular e disruptiva (ABRANCHES, 2019). A primeira sem o financiamento empresarial e com os recursos do Fundo Eleitoral. A crise política e econômica, aprofundada com o impeachment de Dilma em 2016 e a instabilidade do governo Temer, jogou os grandes partidos tradicionais na fogueira da incerteza (MONTE \& VIEIRA, 2018). Os grupos de direita se fortaleciam a cada nova manifestação e a Operação Lava Jato seguia a todo vapor. Apesar do antipetismo em ascensão, o lulismo continuava forte no Nordeste e, particularmente, no Ceará. As principais lideranças políticas continuaram a trabalhar usando os mesmos mecanismos das eleições anteriores: ampliar o leque de alianças para buscar apoios no HGPE e estabelecer uma rede de apoios na capital e no interior. Esse caminho foi trilhado com êxito pelos Ferreira Gomes no Ceará. 
Revista NEP - Núcleo de Estudos Paranaenses, Curitiba, v. 5, n. 2, dez. 2019

Um fenômeno peculiar em 2018 foi a inserção de Ciro Gomes no debate presidencial. O grupo dos Ferreira Gomes se dividiu entre a campanha nacional de Ciro e o processo de reeleição de Camilo e de sua base. Cid Gomes coordenou a campanha do irmão mais velho e foi um dos articuladores de Camilo Santana. A empreitada prometia ser árdua. Diferente de Tasso Jereissati, que deixou de apoiar Serra em 2002 para seguir com Ciro, Camilo tentou jogar com a imparcialidade, sem contrariar os interesses do PT, muito menos os objetivos do grupo que estava inserido. Vale ressaltar que durante seu primeiro mandato, Camilo Santana, mesmo agregando novos aliados junto ao governo, não conseguiu formar seu próprio grupo político, contando ainda com a articulação política dos irmãos Ferreira Gomes.

As estratégias do grupo eram bem distintas. Enquanto se vislumbrava uma campanha relativamente pacífica e sem embates para o governo cearense, o grupo sabia dos grandes desafios da campanha de Ciro Gomes. Contando com poucos aliados, recursos reduzidos e tendo a ex-ministra e agropecuarista Kátia Abreu como vice, a coligação "Brasil Soberano" (PDT, AVANTE) se posicionou como força de centro-esquerda, acreditando que Lula não conseguiria transferir seu capital político para Fernando Haddad. Mesmo fazendo críticas diretas aos governos de Dilma e Temer, Ciro procurou amenizar seu estilo combativo e, por vezes, truculento. A agenda cirista continou centrada na pauta econômica. O programa de Ciro, coordenado por Mangabeira Unger, traçava o modelo de um novo desenvolvimentismo, voltado para o fortalecimento do crédito, redução de juros e investimentos na indústria nacional.

Um das propostas mais polêmicas, intitulada "Nome limpo", visava quitar as dívidas dos brasileiros inadimplentes no SPC (Serviço Proteção ao Crédito). O projeto acabou se tornando uma fábrica de memes nas redes sociais e foi tratada pela grande imprensa e vários especialistas como ação populista irresponsável. Em sua terceira disputa para chegar ao Planalto, Ciro Gomes se saiu bem nos debates e entrevistas, teve pouco espaço na propaganda eleitoral. Diferente dos concorrentes, não desidratou ao longo da campanha, mas também não registrou avanço em regiões dominadas pelo lulismo.

No Ceará, a tarefa do grupo seguia outro percurso. Ao longo de seu primeiro mandato, Camilo Santana colocou em ação a estratégia de desmontar forças oposicionistas (MONTE, 2018). Desarticulou o grupo parlamentar de oposição na Assembleia Legislativa e conseguiu o apoio de 
Eunício Oliveira, presidente do Senado Federal. A aliança com Eunício, apesar de criticada pelo PT, acabou se tornando decisiva para destravar uma série de convênios e projetos emperrados em Brasília após a posse de Michel Temer. Com os repasses federais, somados ao equilíbrio das contas públicas e índices positivos na educação, as pesquisas de opinião apontavam que a gestão Camilo seguia com ótima avaliação, despontando como franco favorito à reeleição daquele ano.

Enquanto isso, a oposição se fragmentava em várias frentes e discursos. O único nome que oferecia possibilidade de competitividade na campanha era a candidatura do senador Tasso Jereissati. O líder tucano prontamente descartou a possibilidade e indicou o neófito general Theophilo formando a coligação "Tá na hora de mudar”, que teve o PROS como único aliado. Historicamente, o situacionismo marca os arranjos políticos no Ceará, contudo, nunca se chegou a tal nível de desorganização e fragilidade das forças de oposição. De 2015 a 2018, perdeu-se a oportunidade de se construir uma alternativa coerente ao projeto liderado pelos Ferreira Gomes. Eunício e Domingos Filho passaram a integrar a eclética aliança governista. Tasso e Capitão Wagner não renovaram suas estratégias, ficando isolados politicamente.

A coordenação da campanha governista foi divida entre o petista Nelson Martins e Cid Gomes. A articulação da dupla produziu a maior coligação da história do Ceará. O arco de apoio de Camilo Santana reuniu 24 partidos - um verdadeiro latifúndio eleitoral com inclinações ideológicas totalmente inconsistentes. A coligação "Por um Ceará cada vez mais forte" contou com a presença de líderes do DEM, PT, PCdoB e PP. Desde a redemocratização, o Ceará não registrava uma vantagem tão esmagadora. Nem mesmo Tasso, no auge do seu poderio, iniciou um pleito com tamanha envergadura. $\mathrm{O}$ apoio de muitas siglas não significa apenas minutos na propaganda eleitoral. Representa uma poderosa rede de vereadores, prefeitos e deputados se articulando diariamente em suas localidades. Com o fim do financiamento empresarial e o inédito fundo eleitoral, ter uma grande coligação trazia consigo mais recursos e a capilarização da candidatura.

A celeuma ficou por conta da composição da chapa para o Senado. Duas vagas estavam em questão. O espaço de Cid Gomes não foi contestado pelos líderes da aliança. O problema ficou por conta do segundo nome. Por decisão de Camilo, os governistas iriam apoiar informalmente a candidatura à reeleição de Eunício Oliveira. Os petistas foram os maiores críticos dessa decisão. Ciro também se manifestou contra - uma vez que seus discursos apontavam o MDB como centro de 
corrupção do país. Seria um lance de autonomia de Camilo na lógica de poder do grupo dos Ferreira Gomes. Uma jogada de risco.

A eleição presidencial se configurou com doze candidaturas. A maioria dos partidos cearenses deliberou pelo o apoio à campanha de Ciro Gomes, mas a adesão à candidatura petista se mostrou significativa. Apesar de ter defendido a composição da chapa Ciro-Haddad, Camilo se apressou em informar que seu projeto comportaria os dois aliados e esse discurso ficou visível no material de campanha - agregando as imagens dos dois líderes. O pragmatismo do grupo já marcava os passos do governador.

A disputa para o governo do estado teve dois candidatos principais: Camilo Santana e General Theophilo. O cenário apontava para mais uma campanha com baixa competitividade no Ceará. Muito diferente do que ocorreu em 2014, quando teve que dividir o apoio dos prefeitos com o então candidato Eunício Oliveira, o governador garantiu o apoio imediato e direito de pelo menos oitenta prefeituras, incluindo aí os grandes municípios cearenses e a capital. A maior fragilidade do grupo continuava a ser a pauta da segurança pública. Foi nesse ponto que a oposição centrou suas forças.

Contando com pouco tempo de rádio e TV, o general Theophilo apresentou pesquisas que apontavam para o expressivo aumento do número de homicídios, roubos e furtos no Ceará e se posicionou como o mais preparado para restabelecer a paz do cearense. $\mathrm{O}$ discurso do general abordava a falta de liderança na área de segurança pública. O slogan da campanha era bem claro: 'Bota moral, General". Entretanto, o esforçou da oposição não foi suficiente para frear o avanço do governador. Contando com mais tempo de rádio e TV, Camilo destacou os avanços na educação, saúde e logística, além de ressaltar que o Ceará estava investindo e pagando seu funcionalismo público, mesmo em uma situação de crise econômica, reforçando assim o perfil de gestão do governo e a necessidade de continuidade de um trabalho com resultados positivos. As peças do HGPE mostravam um governador viajando pelo Ceará, abraçando diferentes aliados e que estaria sempre aberto ao diálogo. Para além do HGPE, Camilo usou com frequência as redes sociais para se comunicar com o eleitorado.

O resultado dessa disputa não fugiu do previsível. Camilo Santana obteve uma vitória estrondosa $(79,96 \%)$. Proporcionalmente, o mais votado do país. Os dilemas da segurança pública 
Revista NEP - Núcleo de Estudos Paranaenses, Curitiba, v. 5, n. 2, dez. 2019

não arranharam as chances do petista, demonstrando a força do ciclo político dos Ferreira Gomes. O candidato mais forte da oposição, general Theophilo, terminou o pleito com apenas 11,3\% dos votos válidos. Para além da reeleição de Camilo e a eleição de Cid Gomes, o grupo conquistou espaços importantes na Assembleia Legislativa. Dos 46 parlamentares, 38 fazem parte da base governista. Entretanto, opositores se fortaleceram. Capitão Wagner teve a maior votação para a Câmara dos Deputados e Eduardo Girão conquistou a segunda vaga para o Senado, desbancando Eunício Oliveira, apoiado diretamente por Camilo Santana.

Com relação à eleição presidencial, Ciro Gomes ficou em terceiro lugar (12,47\%). Não conseguiu furar a polarização Haddad-Bolsonaro, nem se colocar como alternativa ao projeto lulista. Obteve a maioria dos votos no Ceará $(40,95 \%)$, mas se saiu aquém do esperado nas regiões Norte e Nordeste. No segundo turno, Ciro e o PDT se distanciaram da campanha petista, oferecendo apenas um "apoio crítico". As eleições de 2018 demonstraram que o grupo continua muito forte no Ceará, garantindo espaços valiosos na capital e no interior, entretanto, esse poder não conseguiu ser expandido para o cenário nacional.

\section{Considerações finais}

Em linhas gerais, buscou-se, ao longo deste artigo, fazer uma exploração teórica e empírica sobre o conceito de grupo político. Os dados mencionados possibilitam algumas considerações embrionárias, remetendo: a política real, a existência de um chefe político com liderança consolidada e relações verticais e horizontais, ao entendimento das características tradicionais da política brasileira, associadas à modernização das relações políticas, aos partidos como força secundária, ao uso das formas de comunicação e estratégias de marketing, ao adesismo e conflito com grupos políticos antagônicos. A partir de grupos situados no Ceará, considerando suas particularidades e os diferentes contextos históricos, podemos verificar as nuances e atualidade desse arranjo de poder. A análise do funcionamento do grupo dos Ferreira Gomes possibilitou uma reflexão in loco dos elementos abordados no capítulo. 
Revista NEP - Núcleo de Estudos Paranaenses, Curitiba, v. 5, n. 2, dez. 2019

A liderança do grupo é exercida por Ciro e Cid Ferreira Gomes - e entre eles partilhada - que apresentam trajetórias distintas, mas centralizam as decisões, mantendo o grupo coeso. A maioria de seus membros passou por uma socialização em famílias políticas. São oriundos da classe média urbana, políticos profissionais e apresentam um discurso moderno e midiatizado. Não possuem um projeto político definido. Ganharam autonomia do tassismo a partir de 2004, quando começaram a traçar suas próprias estratégias. Com a chegada de Cid Gomes ao governo em 2006, o grupo expandiu consideravelmente o seu número de membros e, paulatinamente, se tornou hegemônico na política cearense. Não há exclusividade de domínio, pois compartilharam espaços com partidos aliados. Passaram por várias siglas, revelando grande pragmatismo e obtendo sucesso ao subordinar as ações do grupo à lógica nacional.

Enganam-se quem acredita que esse modelo não tem sentido na modernidade. Sua lógica já não se assenta na compra de votos ou no curral eleitoral, contudo, seus líderes souberam se adaptar aos tempos da redemocratização, sem abandonar o personalismo, a informalidade e a lógica das redes que percorre esses arranjos. É válido destacar que a categoria de grupo necessita de um maior aprofundamento teórico e metodológico e que sua ação pode ser perfeitamente percebida na esfera municipal e em outros estados brasileiros. Nesse sentido, estudos comparativos e interdisciplinares seriam muito bem vindos. Ao finalizar essa empreitada, fica a noção de que, para além da esfera institucionalizada dos partidos políticos, os grupos ganham destaque na política real e sua formação, atos e decisões não podem passar despercebidos aos olhos dos estudiosos da política.

\section{Referências}

ABRANCHES, Sérgio. Polarização radicalizada e ruptura eleitoral. In: Democracia em risco? 22 ensaios sobre o Brasil hoje São Paulo: Companhia das Letras, 2019. p. 11-34.

ABU-EL-HAJ, Jawdat. O Ceará e o dilema desenvolvimentista brasileiro. Políticas Públicas e Sociedade, Fortaleza, ano 3, nº 6, jul-dez.2003, p. 11-22.

ARRUDA, Assis. Dicionário biográfico: família Gomes Parente. Fortaleza: Premius, 2012.

ARRUDA, José Maria (Org.) A era Jereissati: modernidade e mito. Fortaleza: Edições Demócrito Rocha, 2002. 
Revista NEP - Núcleo de Estudos Paranaenses, Curitiba, v. 5, n. 2, dez. 2019

BARREIRA, César. Os pactos da política cearense: passado e presente. In: HEREDIA, Beatriz Maria Alasia (Org.). Continuidades e rupturas na política cearense. Fortaleza, CE: Universidade Federal do Ceará/Funcap/CNPq-Pronex. Campinas, SP: Pontes Editores, 2008. p. 91113.

BEZERRA, Marcos Octávio. Em Nome das Bases: política, favor e dependência pessoal. Rio de Janeiro: Relume Dumará, 1999.

BOBBIO, N; MATEUCCI, N; PASQUINO, G. (Orgs.). Dicionário de política. $13^{\mathrm{a}}$ ed. Brasília: Ed. $\mathrm{UnB}, 2010$.

BOURDIEU, Pierre. O poder simbólico. Lisboa: Difel, 1989.

CARVALHO, José Murilo de. A construção da ordem: a elite política imperial. Rio de Janeiro: Civilização Brasileira, 2012.

CARVALHO, Rejane Vasconcelos Accioly; Eleições 2014: transição de ciclos políticos no Ceará? Em Debate, Belo Horizonte, v.6, nº 5, p23-36, set.2014.

; LOPES, Monalisa Soares. (2014). Duelo entre candidatos poste: a campanha eleitoral pela prefeitura de Fortaleza em 2012. In: IX Encontro da Associação Nacional de Ciência Política (ABCP). 2014, Brasília. XI Encontro Anual da ABCP - Anais. ABCP: Brasília.

; AQUINO, Jakson Alves. A derrota de Tasso Jereissati na disputa para o Senado em 2010: como entender a dissolução de suas bases eleitorais. Revista Debates, Porto Alegre, v. 5, $\mathrm{n}^{\circ}$ 2, jul.dez. 2011.

.Virgílio, Adauto e César Cals: a política como arte da chefia. In: ARRUDA, José Maria (Org.) A era Jereissati: modernidade e mito. Fortaleza: Edições Demócrito Rocha, 2002. p. 9-34.

Transição democrática brasileira e Padrão Midiático Publicitário da Política. Pontes Editores/UFC; SP, 1999.

CHARAUDEAU, Patrick. Discurso político. São Paulo: Contexto, 2006.

COSTA, Lustosa da. Sobral: cidade de cenas fortes. Fortaleza: ABC Editora, 2003.

DAHL, Robert A. Análise política moderna. Trad. Sérgio Bath. Brasília: Editora da Unb,1981. (Coleção Pensamento Político, 26).

DANTAS NETO, Paulo Fábio. O carlismo para além de ACM: estratégias adaptativas de uma elite política estadual. Cap. 8. In: SOUZA, Celina; DANTAS NETO, Paulo Fábio (Orgs.). Governo, políticas públicas e elites políticas nos estados brasileiros. Rio de Janeiro: Revan, 2006. p. 247286.

DIÁLOGOS POLÍTICOS. Quem controla os votos nos municípios do Ceará. Diálogos Políticos, Fortaleza, 11 out. 2014. Disponível em: <https://dialogospoliticos.wordpress.com/2014/10/11/>. Acesso em: jan. 2016. 
DIÁRIO DO NORDESTE. PSB foi o partido que mais elegeu prefeitos no Ceará. Diário do Nordeste. 28 out. 2010. Disponível em:

$<\mathrm{http}$ ://diariodonordeste.verdesmares.com.br/cadernos/politica/online/psb-foi-o-partido-que-maiselegeu-prefeitos-no-ceara-1.851014>. Acesso em: mai. 2016.

. Convenção oficializa Camilo Santana candidato ao Governo. Diário do Nordeste. 25 de jun. 2014. Disponível em:

$<$ http://diariodonordeste.verdesmares.com.br/cadernos/politica/convencao-oficializa-camilosantana-candidato-ao-governo-1.1048333. Acesso em: abr. 2016.

DIÓGENES, Glória. Ciro Gomes: percursos de uma imagem. In: ARRUDA, José Maria (Org.) A era Jereissati: modernidade e mito. Fortaleza: Edições Demócrito Rocha, 2002. p. 107-124.

DUARTE, Nestor. A ordem privada e a organização nacional: contribuição à Sociologia Política brasileira. Rio de Janeiro: Editora Nacional, 1966.

FARIAS, Airton de. História do Ceará. Fortaleza: Armazém da cultura: 2012.

FERREIRA, Diocleide Lima. A (re)invenção de uma cidade: Cid marketing e a requalificação urbana em Sobral-Ce. 2013. Tese (Doutorado). Programa de Pós-Graduação em Ciências Sociais. Universidade Estadual de Campinas, Campinas, 2013.

FERREIRA, José Gomes. Suplência senatorial, uma análise da representatividade. 80 f. Monografia (especialização) - Centro de Formação, Treinamento e Aperfeiçoamento (Cefor), da Câmara dos Deputados, Curso de Especialização em Instituições e Processos Políticos do Legislativo, Brasília, 2009.

FIRMO, Érico. O futuro do poder político no Nordeste. O povo cenário, Fortaleza, ano I, n ${ }^{\circ} 4$, p. 40$45,2013$.

A genealogia do poder. O povo cenário, Fortaleza, ano I, nº 3, p. 47-53, 2012.

FREITAS, Nilson Almino de. Sobral: opulência e tradição. Sobral: UVA, 2000.

GOMES, Ciro. Um desafio chamado Brasil. Rio de Janeiro: Civilização Brasileira, 2002.

GOMES, Wilson. Transformações da política na era da comunicação de massa. São Paulo: Paulus. 2004 (Comunicação).

HEREDIA, Beatriz Maria Alasia (Org.). Continuidades e rupturas na política cearense. Fortaleza, CE: Universidade Federal do Ceará/Funcap/CNPq-Pronex; Campinas, SP: Pontes Editores, 2008.

LASSWELL, Harold. Política: quem ganha o que, quando, como. Trad. Marco Aurélio dos Santos Chaudon. Editora Unb, 1984. (Coleção Pensamento Político, 64).

LEAL, Victor Nunes. Coronelismo, enxada e voto. 5. ed. São Paulo: Alfa Ômega, 1975.

LIMA JÚNIOR, Olavo Brasil de. (Org.) Sistema partidário brasileiro: diversidade e tendências (1982-1994). Rio de Janeiro: Editora FGV, 1997. 
Revista NEP - Núcleo de Estudos Paranaenses, Curitiba, v. 5, n. 2, dez. 2019 Dossiê Oligarquias do Nordeste no Brasil

ISSN: $2447-5548$

MICHELS, Robert. Sociologia dos partidos políticos. Trad. Arthur Chaudon. Brasília: Editora Unb, 1982. (Coleção Pensamento Político, 53).

MONTE, Cleyton. Pedras no caminho de Camilo. 10/10/2018. Disponível em:

<https://www.opovo.com.br/jornal/opiniao/2018/10/pedras-no-caminho-de-camilo.html> Acesso em: 20 abr. 2019.

As preocupações do eleitor cearense. 22/08/2018. Disponível em: <

https://www.opovo.com.br/jornal/opiniao/2018/08/as-preocupacoes-do-eleitor-cearense.html>. Acesso em: 20 abr. 2019.

. Uma breve análise sobre o favoritismo de Camilo Santana. 19/08/2018. Disponível em:

$<$ https://segundaopiniao.jor.br/uma-breve-analise-sobre-o-favoritismo-de-camilo-santana-porcleyton-monte/>. Acesso em: 21 abr. 2019.

VIEIRA, Paula. A crise política brasileira: atores e estratégias. In: FRANCO, Roberto Kennedy G.; GONZÁLEZ, Pedro Francisco; BEZERRA, Tânia Serra Azul M. (Orgs.). Investigar para transformar. Campina Grande-PB: Realize Editora, 2018. p. 459-472.

Os caminhos do poder no Ceará: a política de alianças nos governos Cid Gomes (20072014). 2016. Tese (Doutorado) - Programa de Pós-graduação em Sociologia. Universidade Federal do Ceará, Fortaleza, 2016.

NEIVA, Pedro Robson Pereira. Os determinantes da existência e dos poderes das câmaras altas: federalismo ou presidencialismo?. Dados, Rio de Janeiro, v. 49, n. 2, p. 269-

299, 2006. Disponível em: $<\mathrm{http}: / / w w w . s c i e l o . b r / s c i e l o . p h p ? s c r i p t=s c i \_a r t t e x t \& p i d=S 0011-$ $52582006000200002 \& \operatorname{lng}=\mathrm{en} \& n \mathrm{~mm}=\mathrm{iso}>$. Acesso em: fev. 2016.

NEIVA, Pedro; IZUMI, Mauricio. Os sem-voto do Legislativo brasileiro: quem são os senadores suplentes e quais os seus impactos sobre o processo legislativo. Opinião Pública, Campinas, v. 18, n. 1, p. 1-21, Jun. 2012 . Disponível em:

http://www.scielo.br/scielo.php?script=sci_arttext\&pid=S0104-

62762012000100001\&lng=en\&nrm=iso Acesso em: fev. 2016

NOBRE, Maria Cristina de Queiroz. Modernização do atraso: a hegemonia burguesa do CIC e as alianças eleitorais da "Era Tasso". 2008. Tese (Doutorado) - Programa de Pós-Graduação em Sociologia. Universidade Federal do Ceará, Fortaleza, 2008.

O ESTADO. Quatro siglas comandam 77,7\% das prefeituras do Ceará. O Estado. 18 jan. 2014. Disponível em: <http://www.oestadoce.com.br/politica>. Acesso em: abr. 2016.

O ESTADÃO. Cid Gomes anuncia filiação em massa para o PROS. O Estadão. 02 out. 2013. Disponível em: $<$ http://politica.estadao.com.br/noticias/geral,cid-gomes-anuncia-filiacao-emmassa-ao-pros, 1080967>. Acesso em: abr. 2016.

O POVO. A mais imprevisível das eleições no Ceará. O Povo. 01 out. 2014. Disponível em: 
$<$ http://www.opovo.com.br/app/colunas/politica/2014/10/01/noticiaspoliticacoluna,3323377/20140110po1914-saiba-mais.shtml>. Acesso em: abr. 2016.

Clãs políticos: famílias controlam 45\% das prefeituras cearenses. O Povo. 07 fev. 2016. Disponível em: <http://www.opovo.com.br/app/opovo/dom/2016/02/06/noticiasjornaldom, 3572309/clas-politicos-familias-controlam-45-das-prefeituras-cearenses.shtml $>$. Acesso em: fev. 2016.

PARENTE, Josênio. Os partidos políticos e a democracia: uma reflexão a partir do caso cearense. In. AGUIAR, Odílio Alves; BATISTA, José Élcio; PINHEIRO, Joceny (Orgs.). Olhares contemporâneos: cenas do mundo em discussão na universidade. Fortaleza: Edições Demócrito Rocha, 2001, p. 210-220.

A fé e a razão na política: conservadorismo e modernidade das elites cearenses. Fortaleza: Edições UFC/UVA, 2000.

Editorial: o Ceará, o Brasil e o mundo: discutindo a Era Jereissati. Políticas Públicas e Sociedade, v.1, n.6, 2003, p.3-6.

QUEIROZ, Maria Isaura Pereira. O mandonismo local na vida política brasileira e outros ensaios. São Paulo: Editora Alfa-Ômega, 1976.

SARAIVA, Ciro J. Depois dos coronéis. Fortaleza: RDS, 2014.

SEILER, Daniel-Louis. Os partidos políticos. Brasília: Editora UnB, 2000.

SEIDL, Ernesto. Estudar os poderosos: a sociologia do poder e das elites. Cap. 6. In: ; GRILL, Igor Gastal (Orgs.). As ciências sociais e os espaços da política no Brasil. Rio de Janeiro: Editora FGV, 2013.

SINGER, André. Os sentidos do lulismo: reforma gradual e pacto conservador. São Paulo: Companhia das Letras, 2012.

WEBER, Max. WEBER, Max. Economia e sociedade: fundamentos da sociologia compreensiva. Brasília: EdUnB, 2009.

Ciência e política: duas vocações. São Paulo: Martin Claret, 2004.

Recebido em: 31 out. 2019

Aceito em: 26 nov. 2019 